\title{
Adrenal hemorrhage in the neonatal intensive care unit: a four-year experience
}

\author{
Atiye Fedakar $\odot$ \\ Department of Pediatrics, Private Afiyet Hospital, Istanbul, Turkey
}

DOI: $10.18621 /$ eurj.421168

\begin{abstract}
Objectives: Adrenal hemorrhage is relatively uncommon and usually underestimated. This study aimed to review the clinical, predisposing factors and ultrasonographic findings of adrenal hemorrhage newborns treated in hospital neonatal intensive care unit.

Methods: The medical records of 14 newborns with adrenal hemorrhage who had been admitted to our neonatal intensive care unit were retrospectively reviewed.

Results: During the study period, 1979 patients were admitted to our neonatal intensive care unit. Throughout the four-year follow-up of patients in the neonatal intensive care unit, adrenal hemorrhage was diagnosed with ultrasonography in $14(0.70 \%)$ infants; thirteen of them were term babies, one of them was a premature baby. Among these 14 patients, 10 (71.4\%) were males, 4 (28.6\%) were females. The average birth weight was $3809.1 \pm 358.5 \mathrm{~g}$. Neonates had risk factors such as: birth trauma in $5(35.7 \%)$ newborns, perinatal asphyxia in $4(28.6 \%)$ newborns, sepsis in $2(14.3 \%)$ newborns, large gestation age in $3(21.4 \%)$ newborns. Resuscitation was performed in $7(50 \%)$ infants in the delivery room. The most common clinical presentations of the newborn with adrenal hemorrhage was hypotonia and lethargy $(n=5 ; 35.7 \%)$. Nine $(64.3 \%)$ newborns had adrenal hemorrhage on the right side, three (21.4\%) of them had bilateral adrenal hemorrhage, and the last two (14.3\%) had adrenal hemorrhage on left side. Resolution time of adrenal hemorrhage was a minimum of one month and maximum of three months in ultrasonographic follow-up.

Conclusions: If there are anamneses of strenuous and traumatic deliveries, and any clinical suspicion, ultrasonography should be performed to exclude adrenal hemorrhage, since it is non-invasive, and also straightforward to apply. In babies with hematomas that are increasing in size, adrenocorticotropic hormone and cortisol levels should be analyzed to prevent any possible adrenal insufficiency, even if there is no clinical sign.
\end{abstract}

Keywords: Adrenal hemorrhage, neonatal intensive care unit, traumatic delivery

Received: May 4, 2018; Accepted: September 6, 2018; Published Online: September 8, 2018

$\mathrm{T}$ he frequency of adrenal hemorrhage in neonates has been reported to be 1.7-2.1 per 1,000 live births. The adrenal gland is extremely sensitive to trauma and asphyxia, because of its relatively large size, and vascularity $[1,2]$. Any factor that causes hy-

poxia leads to a disordered blood flow to the heart, adrenal gland, and the central nervous system [3]. Increased pressure leads to congestion and hypoxia, which cause damage in the endothelial cells and damage in the endothelial cells may result in adrenal hem-

Address for correspondence: Atiye Fedakar, MD., Armağanevler Mah. Akdeniz Cad. Sandra Evleri C blok d-4. 34762 Ümraniye, İstanbul, Turkey E-mail:atyfedakar@hotmail.com 
orrhage $[3,4]$. Its most common occurrence is due to the delivery of large babies, perinatal asphyxia, sepsis, traumatic delivery, coagulation defects, and treatment with anticoagulants. With the wide use of ultrasonography in recent years, the diagnostic frequency of adrenal hemorrhage in neonates is gradually increasing.

AH's clinical signs vary, depending on the degree and diffuseness of bleeding. It can be asymptomatic, or may be diagnosed by chance. The most frequent clinical signs include vomiting, persistent jaundice, unexplained anemia, poor nutrition, and abdominal mass [3-5]. Ultrasonography (USG) is a preferred method in the diagnosis and follow-up of the newborns, since it is non-invasive, rapidly applied, portable, sensitive, and it does not cause radiation [3]. The objective of the present study was to review the related knowledge in literature and investigate the risk factors, clinical, laboratory and ultrasonographic signs, in cases that were delivered in our hospital and followed-up in the neonatal intensive care unit and that were shown to have adrenal hemorrhage in the ultrasonographic examination.

\section{METHODS}

This retrospective study was carried out into newborns with adrenal hemorrhage at our hospital neonatal intensive care unit between 2008-2014. This study was approved by the local Ethics Committee. We reviewed the medical records of patients with adrenal hemorrhage admitted to the neonatal intensive care unit. Infant with congenital anomalies or referred to other centers babies are excluded. We recorded from patients files to reasons for hospitalization, birth weight, gender, delivery type, need for resuscitation in delivery room, existing symptoms, predisposing causes, site of adrenal hemorrhage and resolution time, levels of hemoglobin, biluribin, glucose, sodium, potassium, coagulation test and C-reactive protein (CRP). Coagulation tests included both prothrombin time (PT), and partial thromboplastin time (PTT). Adrenocorticotropic hormone (ACTH) and cortisol levels were measured into many patients with adrenal insufficiency.

In our neonatal intensive care unit protocol, USG is performed in neonatal with perinatal asphyxia; defined as resulting in hypoxemia and hypercapnia, accompanied by metabolic acidosis, neonatal sepsis, unexplained jaundice, infants of diabetic mothers, premature, convulsions, traumatic birth, and large gestation age.

All the patients were examined and diagnosed using USG, and two of the patients were diagnosed using abdominal computed tomography. The patients were followed with serial USG. In cases with adrenal hemorrhage, the first ultrasonographic follow-up examination was performed in 7 days later. USG was in the first month with one week break. Afterwards, ultrasonographic examinations were performed every month for the first three months. Perinatal asphyxia was defined as based on an Apgar score of for $<5 \mathrm{~min}$ and /or neurologic manifestation in postnatal period (for example; seizures, hypotonia, coma and multiorgan system dysfunction).

\section{RESULTS}

During the study period, 1979 patients were admitted to our neonatal intensive care unit.

Table 1. Clinical and laboratory results of infants with adrenal hemorrhage

\begin{tabular}{lcc}
\hline Number of patients & 14 & $\%$ \\
\hline Male & 10 & 71.4 \\
Female & 4 & 28.6 \\
Birth weight & & \\
(g, mean \pm SD) & & \\
Birth trauma & 5 & 35.7 \\
Perinatal ashyxia & 4 & 28.6 \\
Sepsis & 2 & 14.3 \\
Large for gestational & 3 & 21.4 \\
age & & \\
$\begin{array}{l}\text { Resuscitation in } \\
\text { delivery room }\end{array}$ & 7 & 50 \\
Hypotonia and & & \\
lethargy & 5 & 35.7 \\
$\begin{array}{l}\text { Hypotonia and seizure } \\
\text { Respiratory distress }\end{array}$ & & 7.15 \\
$\begin{array}{l}\text { Anemia } \\
\text { Jaundice }\end{array}$ & 1 & 21.4 \\
$\begin{array}{l}\text { Vomit } \\
\text { Adrenal insufficiency } \\
\text { Right sided adrenal } \\
\text { hemorrhage } \\
\text { Bilateral adrenal } \\
\text { hemorrhage }\end{array}$ & 3 & 7.15 \\
$\begin{array}{l}\text { Left sided adrenal } \\
\text { hemorrhage }\end{array}$ & 1 & 7.15 \\
\hline
\end{tabular}




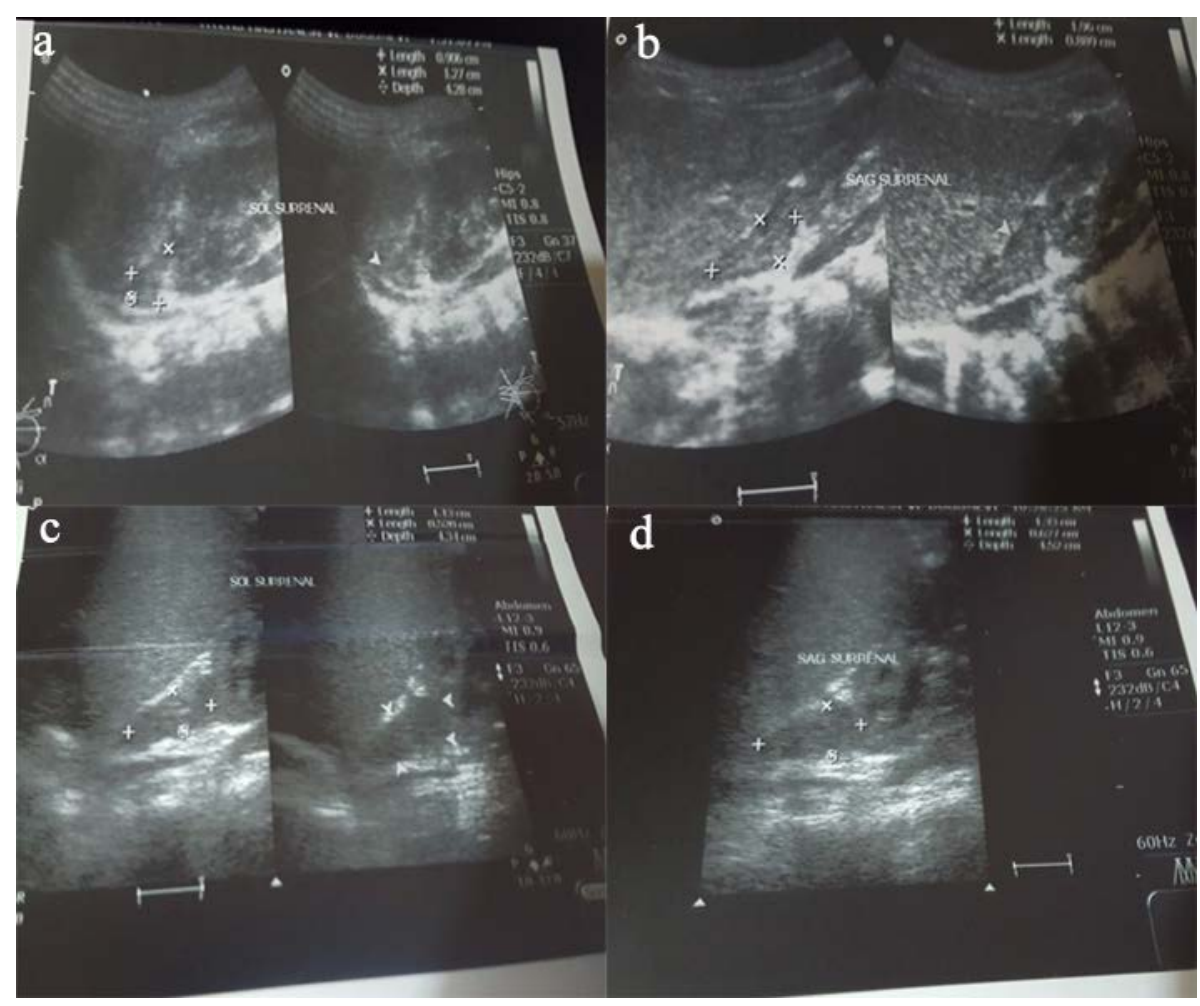

Figure 1. Bilateral adrenal hematoma patient one month apart USG image.

Throughout the four-year follow-up of patients in the neonatal intensive care unit, adrenal hemorrhage was diagnosed with ultrasonography in $14(0.70 \%)$ infants; thirteen of them were term babies, one of them was a premature baby. Among these 14 patients, 10 (71.4\%) were males and $4(28.6 \%)$ were females. The average birth weight was $3809.1 \pm 358.5 \mathrm{gr}(3400-4230 \mathrm{~g})$. Clinical and laboratory results of infants with adrenal hemorrhage are presented in Table 1.

Neonates had risk factors such as: birth trauma in $5(35.7 \%)$ newborns, perinatal asphyxia in $4(28.6 \%)$ newborns, sepsis in $2(14.3 \%)$ newborns, large gestation age in $3(21.4 \%)$ newborns.

The clinical presentations of the newborns were hypotonia and lethargy $(\mathrm{n}=5 ; 35.7 \%)$, sepsis $(\mathrm{n}=2$; $14.3 \%)$, respiratory distress $(\mathrm{n}=3 ; 21.4 \%)$, anemia (n $=1 ; 7.15 \%)$, hypotonia and seizure $(\mathrm{n}=1 ; 7.15 \%)$, vomit $(\mathrm{n}=1 ; 7.15 \%)$, and jaundice $1(\mathrm{n}=1 ; 7.15 \%)$. Resuscitation was performed in 7 (50\%) infants in the delivery room. Nine $(64.3 \%)$ newborns had adrenal hemorrhage on the right side, three $(21.4 \%)$ of them had bilateral adrenal hemorrhage, two (14.3\%) newborn had adrenal hemorrhage on left side. Minimum and maximum adrenal hemorrhage sizes
$40 \times 36 \mathrm{~mm}$ and $12 \times 14 \mathrm{~mm}$ respectively. Bilateral adrenal hematoma patient one month apart USG image is shown is Figure 1.

One patient with jaundice was treated phototherapy applied. One patient with anemia and prolonged PT and PTT was given transfusion and fresh frozen plasma. Three of adrenal hemorrhage patients have with bilateral hematoma. One of them has liver hematoma and plus in the left sternocleidomastoid hemorrhage+ left Klumpke paralys. Liver hematom and the left sternocleidomastoid hemorrhage had been regressed after 3 months. Klumpke paralys was taken because of the physical therapy program. One of them with bilateral adrenal hemorrhage developed in adrenal insufficiency and was treated with both glucorticoid and mineralocorticoid . The other one has plus cranial hemorrhage. Cranial hemorrhage was regressed. Computed tomography image of bilateral adrenal hemorrhage is shown in Figure 2.

The other coagulation tests were all normal for the rest of the patients in our study group. Two patients with bilateral adrenal hemorrhage underwent abdominal computed tomography. There was no 


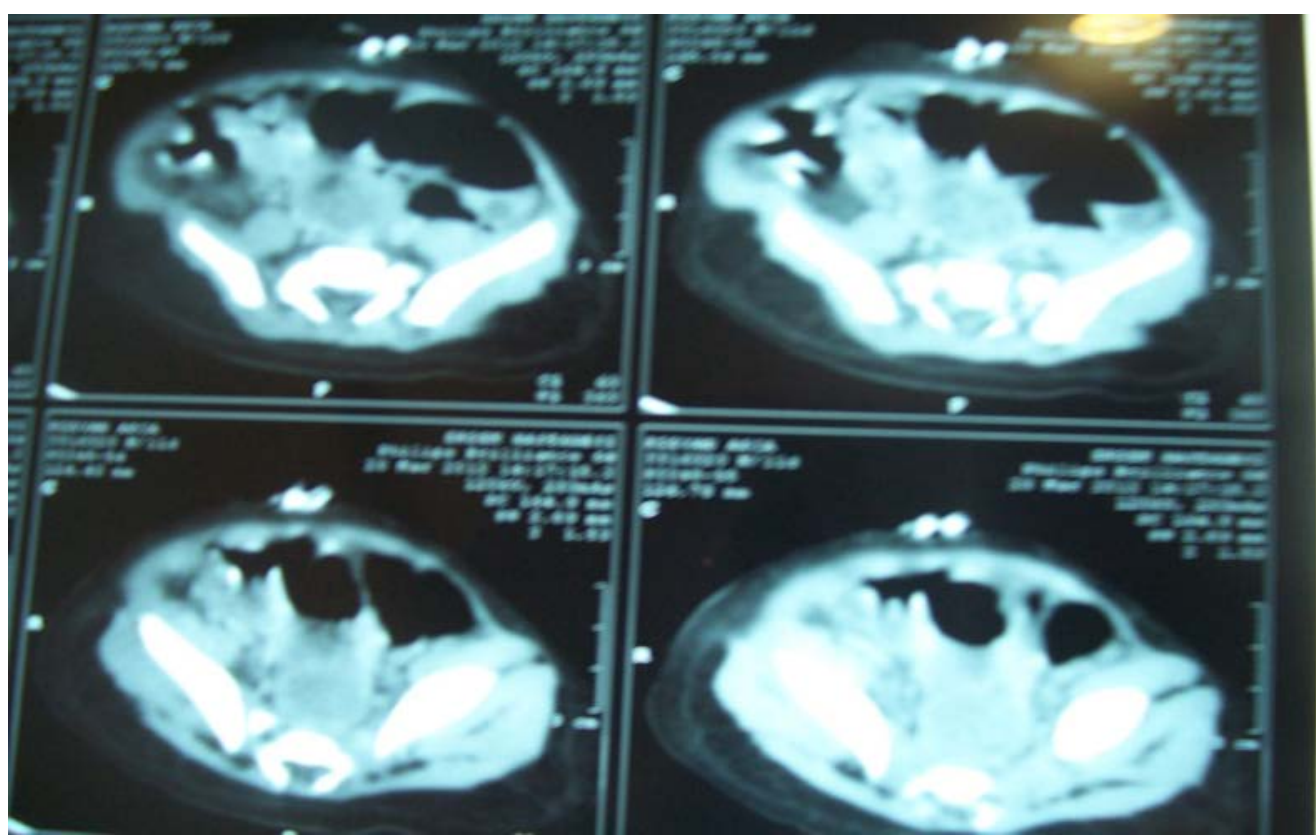

Figure 2. Computed tomography image of bilateral adrenal hemorrhage.

complication due to adrenal hemorrhage. Resolution time of adrenal hemorrhage was a minimum of one month and a maximum of three months in ultrasonographic follow-up.

\section{DISCUSSION}

Adrenal hemorrhage is a relatively common condition. Some cases may be completely asymptomatic and are diagnosed by chance [5]. It was in 1924 that Corcoran and Strauss [6] first reported a neonate was with massive adrenal hemorrhage; this neonate underwent surgery for sustained bleeding. Adrenal gland development begins in the fifth gestational week of the intrauterine life. The adrenal gland is the site for the synthesis of dihydroepiandrostenedione sulphate, which is the main androgenic precursor for the synthesis of placental estrogen in the intrauterine period. This is why the adrenal gland is 20 fold larger in the intrauterine period, compared with that of an adult human, and it is about 2-4 $\mathrm{g}$ at birth [7].

The etiology of adrenal hemorrhage is not yet known, and it is considered to be multifactorial. The larger than normal size of the adrenal gland, and its excessive vascularity, make this organ more susceptible to hemorrhage in neonates. Besides this, any situation that causes hypoxia may result in the interruption of the blood supply to the vital organs. Moreover, the release of endogenous ACTH increases during physiological stress, and thus hypoxia results in damage to the endothelial cells, making them more susceptible to hemorrhage. Some predisposing factors for this situation include strenuous delivery, particularly babies born to diabetic mothers, perinatal asphyxia, trauma, hypoxia, the delivery of a large baby, coagulation defects, shock, and sepsis [8, 9 ]. Its frequency has been reported in the literature to be between 1.7 and 2.1 per 1,000 live births; however, in neonates undergoing USG screening, the frequency is reported as 3\% [2, 10$]$. In the study of Demirel et al. [11], comprising 37 cases that they followed-up for 3.5 years, the frequency of adrenal hemorrhage was reported to be $1.6 \%$; of these babies, $10.8 \%$ experienced traumatic delivery, $10.8 \%$ had perinatal asphyxia, $18.9 \%$ underwent resuscitation in the labor room, and $21.6 \%$ were large for their gestational age [11].

In the study of Mutlu et al. [12], that included 13 cases, the most frequent predisposing factor was reported to be the birth of large babies in term deliveries, and perinatal hypoxia and DIC, secondary to sepsis, in premature babies. In our study, that 
included 14 cases, the frequency of adrenal hemorrhage was $0.70 \%$, which was lower than that reported in literature; the most common predisposing cause was traumatic delivery $(35.7 \%)$.

The right adrenal gland was affected three to four fold more than the left one, due to its possible compression between the liver and spine. The right adrenal vein generally drains directly into the inferior vena cava, and is therefore more usually affected by changes in venous pressure [13]. In the literature, the frequency of bilateral hemorrhage has been reported to be between $8 \%$ and $38 \%$ [5]. Adrenal hemorrhage occurs more frequently in males, than in females [11, 13]. In our study, $71.4 \%$ of the cases were male, and the hematoma was observed in the right adrenal gland in $64.2 \%$ of the cases, which is in accordance with the literature. In the study of Demirel et al. [11], comprising 37 cases, $67.6 \%$ of the patients were male, and adrenal hemorrhage was reported in 24 cases as having occurred mostly in the right gland [11]. The clinical signs are variable, and depend on the quantity of bleeding. Clinical presentation with adrenal hemorrhage can vary from asymptomatic minimal bleeding, to adrenal failure, or fulminate bleeding that result in death. A small amount of bleeding occurs in the capsule, whereas larger amounts of blood escape into the peritoneal space. It results in symptoms like anemia, hemoperitoneum, abdominal mass, persistent jaundice, and scrotal hematoma [5, 14 ]. Adrenal failure related to adrenal hemorrhage is rarely observed, since the hemorrhage is commonly subcapsular, and at least $90 \%$ of the adrenal tissue has to be affected for adrenal insufficiency to occur. The clinical signs of adrenal failure include vomiting, food intolerance, hypoglycemia, electrolyte imbalance, coma, convulsions, and shock [15]. In our patient with bilateral adrenal hemorrhage, we did not detect any clinical signs associated with adrenal failure. Because the size of hematoma was determined to have increased in the second ultrasonographic control, conducted on the postnatal 15th day, precautionary ACTH and cortisol analyses were conducted, and diagnosis was made. Mean ACTH value was 103.0 (reference value: $\leq 46$ ), and cortisol was 3.0 (reference value: $5-25)$. In our patient with bilateral adrenal hemorrhage, who was diagnosed with adrenal failure using laboratory analyses and USG indicators, treatment was started with glucocorticoid and mineralocorticoid. Treatment was ended three months later by gradually decreasing the dosages, and the levels of ACTH and cortisol were maintained within the normal ranges.

One case in our study had anemia. In this patient, PT was also prolonged. PT was improved by transfusions of erythrocyte and fresh frozen plasma. Our patient with jaundice improved with phototherapy. In our patient with Klumpke paralysis, liver complications, sternocleidomastoid injury and bilateral adrenal hemorrhage, the hematomas regressed within three months; however physiotherapy for the Klumpke paralysis is continuing.

Two cases had no symptoms (they are being followed-up for sepsis and respiratory distress, respectively); in these patients, adrenal hemorrhage was determined in the ultrasonographic evaluation, which was conducted due to their being large babies. In the study of Chang et al., which continued for four years, 1,373 asymptomatic babies underwent USG, and of these babies, ten were determined to exist with adrenal hemorrhage [9]. When USG is routinely applied for large babies without anamneses of strenuous delivery, it might be possible to diagnose many asymptomatic cases.

In most cases, conservative treatment is sufficient. The vital signs have to be followed-up, and hydration must be maintained. In cases with uncontrolled massive bleeding, surgery is indicated [16]. In our series, none of the cases required surgical treatment, and conservative therapy was sufficient for improvement. In the differential diagnosis of adrenal hemorrhage, one must primarily consider neuroblastoma or adrenal abscess, which cause intraabdominal mass, and other diseases, like cystic renal illnesses. Abdominal USG is especially useful in differential diagnosis, and also in diagnosis and follow-ups. In serial USG, resolution occurs with hematomas, but the masses do not get smaller[14 ]. We have followed up our cases with serial USG. The patients underwent ultrasonography once a week in the first month, which was followed by ultrasonographic investigations monthly. In two cases, abdominal tomography was applied. In the study of Chang et al. [9], which included ten cases, hematomas were found to regress within one to four months. Hematomas were determined to regress within three to nine months in the study by Demirel et al. [11], 
comprising 37 cases, and within one to four months in the study of Mutlu et al. [12], that included 13 cases. In our study, comprising 14 cases, hematomas regressed within one to three months, and this was in accordance with the literature. There were no complications in our patients.

\section{CONCLUSION}

Adrenal hemorrhage frequently develops secondary to traumatic delivery and asphyxia. If there are anamneses of strenuous and traumatic deliveries, and any clinical suspicion, USG should be performed to exclude adrenal hemorrhage, since it is noninvasive, and also straightforward to apply. In large babies, USG should be recommended in order not to overlook these cases, even in the absence of an anamnesis of strenuous delivery, and in cases of a normal delivery. In babies with hematomas that are increasing in size, ACTH and cortisol levels should be analyzed to prevent any possible adrenal insufficiency, even if there is no clinical sign. In order not to overlook these cases, patients attending with nonspecific signs like jaundice, unexplained anemia, vomiting, and decreased sucking, specifically in the neonatal period, and if there is an anamnesis of strenuous delivery, a possible adrenal hemorrhage should always be considered.

\section{Conflict of interest}

The authors disclosed no conflict of interest during the preparation or publication of this manuscript.

\section{Financing}

The authors disclosed that they did not receive any grant during conduction or writing of this study.

\section{REFERENCES}

[1] Felc Z. Ultrasound in screening for neonatal adrenal hemorrhage. Am J Perinatol 1995;12:363-6.

[2] Mangurten HH. Birth injuries. In: Martin RJ, Fanaroff AA, Walsh MC (eds). Fanaroff and Martin's Neonatal Perinatal Medicine-Diseases of the Fetus and Newborn, 8th ed., Philadelphia: Mosby Elsevier; 2006: pp.529-59.

[3] Koplewitz BZ, Daneman A, Cutz E, Hellmann J. Neonatal adrenal congestion: a sonographic-pathologic correlation. Pediatr Radiol 1998;28:958-62.

[4] Wang CH, Chen SJ, Yang LY, Tang RB. Neonatal adrenal hemorrhage presenting as a multiloculated cystic mass. .J Chin Med Assoc 2008;71:481-4.

[5 ] Rumińska M, Welc-Dobies J, Lange M, Maciejewska J, Pyrzak B, Brzewski M. [Adrenal hemorrhage in neonates: risk factors and diagnostic and clinical procedure]. Med Wieku Rozwoj 2008;12:457-62. [Article in Polish]

[6] Corcoran WJ, Strauss AA. Suprarenal hemorrhage in the newborn. JAMA 1924;82:626-30.

[7] Schwärzler P, Bernard JP, Senat MV, Ville Y. Prenatal diagnosis of fetal adrenal masses: differentiation between hemorrhage and solid tumor by color Doppler sonography. Ultrasound Obstet Gynecol 1999;13:351-5.

[8] Simon DR, Palese MA. Clinical update on the management of adrenal hemorrhage. Curr Urol Rep 2009;10.78-83.

[9] Chang HY, Yeung CY, Hsu CH, Lee HC, Lee YJ, Lin D S, et al. Neonatal adrenal hemorrhage: four years' experience. Clin Neonatol 2002;9:10-5.

[10] Gunlemez A, Karadag A, Degirmencioglu H, Uras N, Turkay S. Management of severe hyperbilirubinemia in the newborn: adrenal hematoma revisited. J Perinatol 2005;25:8034.

[11] Demirel N, Baş AY, Zenciroğlu A, Taşci-Yildiz Y. Adrenal bleeding in neonates: report of 37 cases. Turk J Pediatr 2011;53:43-7.

[12] Mutlu M, Karagüzel G, Aslan Y, Cansu A, Ökten A. Adrenal hemorrhage in newborns: a retrospective study. World J Pediatr 2011;7:355-7.

[13] Avolio L, Fusillo M, Ferrari G, Chiara A, Bragheri R. Neonatal adrenal hemorrhage manifesting as acute scrotum:timely diagnosis prevents unnecessary surgery. Urology 2002;59:601.

[14] Velaphi SC, Periman JM. Neonatal adrenal hemorrhage: clinical and abdominal sonografic finding. Clin Pediatr 2001;40:545-8.

[15] Arayıcı S, Öncel MY, Sarı FN, Dizdar EA, Uraş N, Aycan $Z$, et al. A case of a newborn infant with adrenal insufficiency due to bilateral adrenal hemorrhage Turk J Pediatr 2011;57:1024.

[16] Khuri FJ, Alton DJ, Hardy BE, Cook GT, Churchill BM. Adrenal hemorrhage in neonates:Report of 5 cases and review of the literature. J Urology 1980;124:684-7. 